\title{
The Importance of Access to Bilateral Hearing through Cochlear Implants in Children
}

\author{
Karen A. Gordon, Ph.D., C.C.C.-A., Reg. CASLPO, ${ }^{1,2,4}$ \\ Blake C. Papsin, M.D., FRCSC, 1,3,4 \\ Vicky Papaioannou, MCISc, Reg. CASLPo, ${ }^{2,3,4}$ and \\ Sharon L. Cushing, M.D., FRCSC ${ }^{1,3,4}$
}

\section{ABSTRACT}

Children with hearing loss require early access to sound in both ears to support their development. In this article, we describe barriers to providing bilateral hearing and developmental consequences of delays during early sensitive periods. Barriers include late identification of hearing loss in one or both ears and delayed access to intervention with hearing devices such as cochlear implants. Effects of delayed bilateral input on the auditory pathways and brain are discussed as well as behavioral effects on speech perception and other developmental outcomes including language and academics. Evidence for these effects has supported an evolution in cochlear implant candidacy in children that was started with unilateral implantation in children with profound deafness bilaterally to bilateral implantation to implantation of children with asymmetric hearing loss including children with single-side deafness. Opportunities to enhance the developmental benefits of bilateral hearing in children with hearing loss are also discussed including efforts to improve binaural/spatial hearing and consideration of concurrent vestibular deficits which are common in children with hearing loss.

KEYWORDS: deafness, bilateral cochlear implants, bimodal hearing, universal hearing screening, sensitive periods, cytomegalovirus, binaural/spatial hearing, aural preference

\footnotetext{
${ }^{1}$ Archie's Cochlear Implant Laboratory, The Hospital for Sick Children, Toronto, Canada; ${ }^{2}$ Department of Communication Disorders, The Hospital for Sick Children, Toronto, Canada; ${ }^{3}$ Department of Otolaryngology, The Hospital for Sick Children, Toronto, Canada; ${ }^{4}$ Department of Otolaryngology - Head and Neck Surgery, University of Toronto, Toronto, Canada.

Address for correspondence: Karen A. Gordon, Ph.D., C.C.C.-A., Reg CASLPO, Archie's Cochlear Implant Laboratory, Room 6D08, The Hospital for Sick Children,
}

555 University Avenue, Toronto, ON M5G 1X8 (e-mail: karen.gordon@utoronto.ca).

Barriers to Cochlear Implant Access: Acknowledging the Challenges, Changing the Future; Guest Editor, Sarah Sydlowski, Au.D., Ph.D., M.B.A.

Semin Hear 2021;42:381-388. (C) 2021. Thieme. All rights reserved. Thieme Medical Publishers, Inc., 333 Seventh Avenue, 18th Floor, New York, NY 10001, USA DOI: https://doi.org/10.1055/s-0041-1739371.

ISSN 0734-0451. 
Audiologists provide audibility of sounds, particularly speech, to individuals with hearing loss. In children, this means identifying the presence of a permanent hearing loss, establishing the degree of loss, and then determining whether a hearing device is needed. The timing of each of these stages is essential in children to support language development during early sensitive periods. ${ }^{1,2}$ It has also come to light that providing access to sound in both ears is important in children with hearing loss ${ }^{3,4}$; there are clear benefits of bilateral hearing and also significant detriments of relying on one ear to hear. ${ }^{5,6}$ Yet, bilateral hearing can be challenging to provide in children. In this article, we aim to identify existing barriers to bilateral hearing in children with hearing loss and to highlight clinical opportunities to reduce these barriers.

\section{BARRIERS DELAY BILATERAL HEARING IN CHILDREN DURING SENSITIVE PERIODS IN DEVELOPMENT}

\section{Financial/Economic Barriers}

One of the most practical barriers to providing bilateral hearing in children is economic/financial concern. Bilateral hearing devices presently double costs to children's families and to public and private funders of the devices. This economic concern is exacerbated in children with severe to profound hearing loss who need two cochlear implants to access sound in both ears. Increased costs of bilateral cochlear implants may be refused by insurance providers or other funding agencies including governmental health care systems. Indeed, bilateral cochlear implants are not a reality for children in many countries for this reason. ${ }^{7}$ The additional costs of cochlear implantation may also be a limiting factor for securing funding in children who have one deaf ear but who have better residual hearing in the other ear despite evidence of cost-effectiveness in adults. ${ }^{8}$

Although a concern in the short term, the economic implications of providing bilateral hearing must be weighed in context with the developmental requirements of children given the long-term effects of auditory deprivation. The immature brain undergoes rapid changes throughout the first months and years of life ${ }^{9}$ and is thus vulnerable to abnormal development during this time. ${ }^{1}$ Without hearing during early life, the developing brain reorganizes to process remaining sensory input such as vision (crossmodal plasticity), making it difficult to restore functional hearing later. ${ }^{10-12}$ Delays in language acquisition are also difficult to reverse. ${ }^{2,13}$ It is true that audibility can be restored to one ear in children to promote auditory development ${ }^{14,15}$ and language, ${ }^{16}$ but we know from children with single-side hearing that this hearing is not sufficient to avoid deficits in oral language development and academic outcomes. ${ }^{6,17,18}$ These challenges have their own economic implications ${ }^{19-21}$ and reflect the loss of important listening skills that require hearing in both ears including sound localization ${ }^{22}$ and detection of one voice among many different sounds/noise. ${ }^{23}$

\section{Barriers Result from Delays in Identification}

Barriers to providing bilateral hearing in children during early sensitive periods of development $^{24,25}$ are also related to delays in identification of hearing loss. Newborn hearing screening programs have proven to be instrumental in providing early access to sound for children with congenital hearing loss. ${ }^{2}$ However, these programs are not available in all countries and, even in countries where they do exist, they can be inaccessible in some regions. Most recently, some newborn hearing screening programs were halted in the initial response to the COVID-19 pandemic and catch-up screening was not necessarily performed. When in place, newborn hearing screening programs typically assess hearing in each ear which allows bilateral as well as unilateral hearing problems to be identified. ${ }^{26,27}$ It is important that screeners do not dismiss an abnormal finding in one ear as spurious because of a pass result in the other ear. Another concern regarding newborn hearing screening is that many children with initially good access to sound will have progressive deterioration of their hearing. ${ }^{28}$ One of the leading causes of progressive hearing loss in children is congenital cytomegalovirus $(\mathrm{cCMV}){ }^{29}$ In our 
Canadian province of Ontario, universal screening of $\mathrm{cCMV}$ is completed through PCR analyses of bloodspots in all newborns in addition to hearing screening. ${ }^{30}$ In this program, infants identified with cCMV undergo regular monitoring of their hearing in both ears. This program has been very important in identifying asymmetric progressive hearing loss in children because cCMV is known to be associated with single-side deafness in young children. $^{31,32}$

Given the importance of hearing development in early life, children with hearing loss must receive hearing devices without delay. Outcomes of early intervention are clear in children who need hearing aids, cochlear implants, or a combination of both. ${ }^{2,13,33,34}$ These studies demonstrate that delays of even months in implantation can lead to gaps in development. Adherence to the early hearing detection and intervention guidelines for hearing screening by 1 month of age, full hearing assessment by 3 months of age, and early intervention by 6 months of age reduces age at cochlear implantation by approximately 15 months which, in turn, improves language skills. ${ }^{2}$ These guidelines have been adopted into the 2019 position statement of the Joint Committee on Infant Hearing. ${ }^{35}$ Language gaps with delays to device activation are exacerbated with increasing severity of hearing loss. ${ }^{13}$ There is sufficient evidence for candidacy of cochlear implants to infants younger than 12 months ${ }^{34}$ and for providing cochlear implants to limit asymmetric hearing. ${ }^{33,36}$

Candidacy for cochlear implantation is typically determined through an evidence-based multidisciplinary process ${ }^{37,38}$ and cochlear implant candidacy has evolved significantly since this device was first provided to children in the mid-1990s. This means that cochlear implants were not provided or were delayed in some children who were not initially cochlear implant candidates. Cochlear implants were initially provided in only one ear to children with profound hearing loss in both ears. Later, hearing aids were used to provide sound to the unimplanted ear with some benefits for speech perception. ${ }^{39,40}$ The success of "bimodal hearing" (a cochlear implant in one ear and acoustic hearing through a hearing aid in the other) lead to suggestions that bilateral cochlear implants might provide children with better hearing than one cochlear implant. Children who were experienced unilateral cochlear implants received a second device and showed improved abilities to hear speech in noise and some spatial hearing skills. ${ }^{5,41,42}$ Still, many of these children continued to show asymmetric hearing with an "aural preference" for listening with their first cochlear implant. ${ }^{3,24,33,43}$ Changes in the auditory cortex, measured by multichannel electroencephalography, revealed that unilateral cochlear implant use promoted abnormal strengthening from the stimulated ear to both auditory cortices. $4,24,44,45$ Further studies showed that providing bilateral cochlear implants in the same surgery (simultaneously) at young ages was cost-effective ${ }^{46,47}$ and better able to support development of pathways from both ears to auditory cortices $4,24,48$ than providing bilateral implants sequentially with long interimplant delays. The cortical data are supported by findings of remaining asymmetries in hearing in children with interimplant delays exceeding approximately 2-3 years relative to children receiving bilateral implants simultaneously. ${ }^{33,43,49}$

\section{Barriers Due to Configuration of Hearing Loss}

Advantages of bilateral hearing in children with profound bilateral deafness through bimodal hearing and bilateral cochlear implants lead to questions about the use of cochlear implantation in children with asymmetric hearing loss. This latter group of children did not historically meet cochlear implant candidacy because they had good access to sound in one ear through hearing aids or even through one normal hearing ear. However, their deaf ear was deprived of sound and they were at risk of poorer hearing outcomes relative to their peers with hearing loss who received intervention to provide bilateral hearing. Several centers have provided cochlear implants to such children with good outcomes. ${ }^{33,36,39,50-53}$ Cortical reorganization which increases preference for the better hearing ear is more limited when the delay to cochlear implantation is reduced ${ }^{25}$ and children implanted more quickly also show improved speech perception when using their bimodal 
devices compared with either device alone. ${ }^{33}$ Outcomes in children with bimodal devices have also revealed that cochlear implants can provide better hearing benefits than hearing aids for children with severe hearing loss. ${ }^{36,50}$ With this evidence, bimodal hearing device users with severe hearing loss are now considered candidates to receive a cochlear implant in the initially better hearing ear.

Successful use of bimodal devices in children with asymmetric hearing loss has also led to the consideration of cochlear implantation in individuals with single-side deafness. ${ }^{31,54-57}$ Developmental effects of unilateral hearing loss in children on language and learning have been reported for many decades ${ }^{6,17}$; yet, interventions were limited to removing the head shadow effect of the deaf ear by sending sound from that side to the normal hearing ear through CROS hearing aids or bone conduction devices. Bilateral hearing could not be provided through these methods and was thought to remain out of reach for these children because of concerns that a hearing device in the deaf ear might disrupt the hearing in the normal hearing ear. Adults with singleside deafness have shown clear benefits of cochlear implantation ${ }^{8,58,59}$ and studies are presently underway to determine the effectiveness of implantation in children with singleside deafness. ${ }^{31,56,57,60}$ Early findings show that many children with single-side deafness do use their cochlear implants daily. ${ }^{55-57,60}$ Cochlear implants can also restore representation of the deaf ear in the auditory cortex when provided to young children with single-side deafness ${ }^{32,61}$ but cannot protect children with later onset of deafness from deterioration of auditory pathways from the newly deafened ear. ${ }^{61}$

\section{OPPORTUNITIES TO IMPROVE BINAURAL HEARING IN CHILDREN}

Evidence thus far supports providing bilateral hearing in children with the most appropriate device in each ear without delay. ${ }^{3}$ This will best support development of hearing in each ear and protect the bilateral auditory pathways from asymmetric function. However, efforts to rapidly provide hearing to each ear in early development will need to be further supported.
Looking ahead, we will need to address the remaining gaps in hearing for children using devices such as hearing aids and cochlear implants. It is clear that children with hearing loss require considerable effort to hear ${ }^{18,62-65}$ and we should expect that this has consequences for their overall development.

Children with bilateral cochlear implants still have poor abilities to locate sounds in space $e^{5,66-68}$ and to detect changes in the time differences of one sound reaching the two ears ${ }^{69,70}$ which may result, in part, from the uncoordinated input provided by independent devices used in each ear. ${ }^{71,72}$ Improved outcomes for children with hearing loss will require advances in how hearing devices represent sound such as speech and improvements in how the auditory system processes this input. Advances should also promote binaural hearing by reducing inaccuracies in interaural level and timing differences and mismatched place of stimulation that can occur between devices and ears. ${ }^{71,73,74}$ Furthermore, we should think about additional therapeutic techniques that can help children best use the sound they receive through hearing devices. Currently, therapies are focused appropriately on establishing language in children. Beyond this, novel techniques are needed to help children acquire spatial hearing so they can use this language in more complex listening situations. Additionally, we need to consider the potential impact of concurrent vestibular deficits in children with hearing loss on spatial and cognitive development. ${ }^{75,76}$ As in the past, coordinated research can add essential evidence to shape changes in our clinical management of children with hearing loss.

\section{SUMMARY AND CONCLUSION}

Present evidence indicates that barriers which delay intervention in children with hearing loss have significant consequences to auditory development, language acquisition, cognitive function, and academic learning. These barriers include delayed identification of hearing loss which can be avoided in part through universal hearing screening programs and programs that identify infants at high risk for hearing loss such as those with cCMV. Further delays in providing 
audible sound to children with permanent hearing loss must also be avoided and efforts are needed to provide hearing in both ears. By reducing these barriers, we expect to improve overall development in children with hearing loss. Coordinated research and innovation aims to further reduce gaps between children with hearing loss and their typically developing peers.

\section{CONFLICTS OF INTEREST}

B.C.P. and S.L.C. are on the speaker's bureau for Cochlear Corporation, S.L.C. is on the speaker's bureau for Interacoustics and received royalties as a Plural Publishing editor for Balance Disorders in the Pediatric Population, K. A.G. is an adjunct faculty at Salus University, S. L.C. and B.C.P. hold Patent \#: 7041-0: Systems and Methods for Balance Stabilization Sponsored Research Agreement-Cochlear Americas.

\section{REFERENCES}

1. Kral A, Hartmann R, Tillein J, Heid S, Klinke R. Delayed maturation and sensitive periods in the auditory cortex. Audiol Neurotol 2001;6(06): 346-362

2. Yoshinaga-Itano C, Sedey AL, Wiggin M, Mason CA. Language outcomes improved through early hearing detection and earlier cochlear implantation. Otol Neurotol 2018;39(10):1256-1263

3. Gordon K, Henkin Y, Kral A. Asymmetric hearing during development: the aural preference syndrome and treatment options. Pediatrics 2015;136(01): 141-153

4. Gordon K, Kral A. Animal and human studies on developmental monaural hearing loss. Hear Res 2019;380:60-74

5. Litovsky RY, Gordon K. Bilateral cochlear implants in children: effects of auditory experience and deprivation on auditory perception. Hear Res 2016;338:76-87

6. Bess FH, Tharpe AM. Unilateral hearing impairment in children. Pediatrics 1984;74(02): 206-216

7. Swami H, Ap A, Shivanand S. Cost-effectiveness of pediatric unilateral/bilateral cochlear implant in a developing country. Otol Neurotol 2021;42(01): e33-e39

8. Marx M, Mosnier I, Venail F, et al. Cochlear implantation and other treatments in single-sided deafness and asymmetric hearing loss: results of a national multicenter study including a randomized controlled trial. Audiol Neurootol (Published online March 31, 2021). Doi: 10.1159/000514085

9. Huttenlocher PR, Dabholkar AS. Regional differences in synaptogenesis in human cerebral cortex. J Comp Neurol 1997;387(02):167-178

10. Meredith MA, Kryklywy J, McMillan AJ, Malhotra S, Lum-Tai R, Lomber SG. Crossmodal reorganization in the early deaf switches sensory, but not behavioral roles of auditory cortex. Proc Natl Acad Sci U S A 2011;108(21):8856-8861

11. Lee HJ, Giraud AL, Kang E, et al. Cortical activity at rest predicts cochlear implantation outcome. Cereb Cortex 2007;17(04):909-917

12. Giraud AL, Lee HJ. Predicting cochlear implant outcome from brain organisation in the deaf. Restor Neurol Neurosci 2007;25(3-4):381-390

13. Ching TYC, Dillon H, Button L, et al. Age at intervention for permanent hearing loss and 5-year language outcomes. Pediatrics 2017;140(03): e20164274

14. Ponton CW, Eggermont JJ. Of kittens and kids: altered cortical maturation following profound deafness and cochlear implant use. Audiol Neurotol 2001;6(06):363-380

15. Sharma A, Dorman M, Spahr A, Todd NW. Early cochlear implantation in children allows normal development of central auditory pathways. Ann Otol Rhinol Laryngol Suppl 2002;189:38-41

16. Geers A, Brenner C, Davidson L. Factors associated with development of speech perception skills in children implanted by age five. Ear Hear 2003;24 (1, Suppl):24S-35S

17. Lieu JE, Tye-Murray N, Karzon RK, Piccirillo JF. Unilateral hearing loss is associated with worse speech-language scores in children. Pediatrics 2010;125(06):e1348-e1355

18. Lieu JE. Speech-language and educational consequences of unilateral hearing loss in children. Arch Otolaryngol Head Neck Surg 2004;130(05):524-530

19. Karande S, Ramadoss D, Gogtay N. Economic burden of slow learners: a prevalence-based cost of illness study of its direct, indirect, and intangible costs. J Postgrad Med 2019;65(04):219-226

20. Le HND, Gold L, Mensah F, et al. Service utilisation and costs of language impairment in children: the early language in Victoria Australian population-based study. Int J Speech Lang Pathol 2017;19(04):360-369

21. GBD 2019 Hearing Loss Collaborators. Hearing loss prevalence and years lived with disability, 1990-2019: findings from the Global Burden of Disease Study 2019. Lancet 2021;397 (10278):996-1009

22. Grothe B, Pecka M. The natural history of sound localization in mammals - a story of neuronal inhibition. Front Neural Circuits 2014;8:116 
23. Hawley ML, Litovsky RY, Culling JF. The benefit of binaural hearing in a cocktail party: effect of location and type of interferer. J Acoust Soc Am 2004;115(02):833-843

24. Gordon KA, Wong DD, Papsin BC. Bilateral input protects the cortex from unilaterally-driven reorganization in children who are deaf. Brain 2013;136(Pt 5):1609-1625

25. Polonenko MJ, Papsin BC, Gordon KA. Delayed access to bilateral input alters cortical organization in children with asymmetric hearing. Neuroimage Clin 2017;17:415-425

26. Hyde ML. Newborn hearing screening programs: overview. J Otolaryngol 2005;34(Suppl 2):S70-S78

27. Patel H, Feldman M. Universal newborn hearing screening. Paediatr Child Health 2011;16(05): 301-310

28. Fitzpatrick EM, Whittingham J, Durieux-Smith A. Mild bilateral and unilateral hearing loss in childhood: a 20-year view of hearing characteristics, and audiologic practices before and after newborn hearing screening. Ear Hear 2014;35 (01):10-18

29. Goderis J, De Leenheer E, Smets K, Van Hoecke $\mathrm{H}$, Keymeulen A, Dhooge I. Hearing loss and congenital CMV infection: a systematic review. Pediatrics 2014;134(05):972-982

30. Khurana P, Cushing SL, Chakraborty PK, et al. Early hearing detection and intervention in Canada. Paediatr Child Health 2020;26(03): 141-144

31. Cushing SL, Gordon KA, Sokolov M, Papaioannou V, Polonenko M, Papsin BC. Etiology and therapy indication for cochlear implantation in children with single-sided deafness: retrospective analysis. HNO 2019;67(10):750-759

32. Polonenko MJ, Gordon KA, Cushing SL, Papsin BC. Cortical organization restored by cochlear implantation in young children with single sided deafness. Sci Rep 2017;7(01):16900

33. Polonenko MJ, Papsin BC, Gordon KA. Limiting asymmetric hearing improves benefits of bilateral hearing in children using cochlear implants. Sci Rep 2018;8(01):13201

34. Nicholas JG, Geers AE. Spoken language benefits of extending cochlear implant candidacy below 12 months of age. Otol Neurotol 2013;34(03): 532-538

35. Position Statement: Principles and guidelines for early hearing detection and intervention programs. Journal of Early Hearing Detection and Intervention 2019;4 (02):1-44. DOI: https://doi.org/10.15142/fptk-b748

37. Daya H, Figueirido JC, Gordon KA, Twitchell K, Gysin C, Papsin BC. The role of a graded profile analysis in determining candidacy and outcome for cochlear implantation in children. Int J Pediatr Otorhinolaryngol 1999;49(02):135-142
38. Nikolopoulos TP, Gibbin KP, Dyar D. Predicting speech perception outcomes following cochlear implantation using Nottingham children's implant profile (NChIP). Int J Pediatr Otorhinolaryngol 2004;68(02):137-141

39. Morera C, Manrique M, Ramos A, et al. Advantages of binaural hearing provided through bimodal stimulation via a cochlear implant and a conventional hearing aid: a 6-month comparative study. Acta Otolaryngol 2005;125(06):596-606

40. Ching TYC, Incerti P, Hill M. Binaural benefits for adults who use hearing aids and cochlear implants in opposite ears. Ear Hear 2004;25(01):9-21

41. Kühn-Inacker H, Shehata-Dieler W, Müller J, Helms J. Bilateral cochlear implants: a way to optimize auditory perception abilities in deaf children? Int J Pediatr Otorhinolaryngol 2004;68(10): 1257-1266

42. Papsin BC, Gordon KA. Bilateral cochlear implants should be the standard for children with bilateral sensorineural deafness. Curr Opin Otolaryngol Head Neck Surg 2008;16(01):69-74

43. Illg A, Sandner C, Büchner A, Lenarz T, Kral A, Lesinski-Schiedat A. The optimal inter-implant interval in pediatric sequential bilateral implantation. Hear Res 2019;372:80-87

44. Jiwani S, Papsin BC, Gordon KA. Early unilateral cochlear implantation promotes mature cortical asymmetries in adolescents who are deaf. Hum Brain Mapp 2016;37(01):135-152

45. Jiwani S, Papsin BC, Gordon KA. Central auditory development after long-term cochlear implant use. Clin Neurophysiol 2013;124(09):1868-1880

46. Lammers MJ, Grolman W, Smulders YE, Rovers MM. The cost-utility of bilateral cochlear implantation: a systematic review. Laryngoscope 2011;121 (12):2604-2609

47. Health Quality Ontario. Bilateral cochlear implantation: a health technology assessment. Ont Health Technol Assess Ser 2018;18(06):1-139

48. Gordon KA, Valero J, van Hoesel R, Papsin BC. Abnormal timing delays in auditory brainstem responses evoked by bilateral cochlear implant use in children. Otol Neurotol 2008;29(02):193-198

49. Cullington HE, Bele D, Brinton JC, et al. United Kingdom national paediatric bilateral project: demographics and results of localization and speech perception testing. Cochlear Implants Int 2017;18 (01):2-22

50. Gifford RH, Driscoll CL, Davis TJ, Fiebig P, Micco A, Dorman MF. A within-subject comparison of bimodal hearing, bilateral cochlear implantation, and bilateral cochlear implantation with bilateral hearing preservation: high-performing patients. Otol Neurotol 2015;36(08):1331-1337

51. Ching TY, Day J, Van Buynder P, et al. Language and speech perception of young children with 
bimodal fitting or bilateral cochlear implants. Cochlear Implants Int 2014;15(Suppl 1):S43-S46

52. Illg A, Bojanowicz M, Lesinski-Schiedat A, Lenarz T, Büchner A. Evaluation of the bimodal benefit in a large cohort of cochlear implant subjects using a contralateral hearing aid. Otol Neurotol 2014;35(09):e240-e244

53. Polonenko MJ, Giannantonio S, Papsin BC, Marsella P, Gordon KA. Music perception improves in children with bilateral cochlear implants or bimodal devices. J Acoust Soc Am 2017;141(06):4494-4507

54. Cullington HE, Zeng FG. Bimodal hearing benefit for speech recognition with competing voice in cochlear implant subject with normal hearing in contralateral ear. Ear Hear 2010;31(01):70-73

55. Arndt S, Prosse S, Laszig R, Wesarg T, Aschendorff A, Hassepass F. Cochlear implantation in children with single-sided deafness: does aetiology and duration of deafness matter? Audiol Neurotol 2015;20(Suppl 1):21-30

56. Ganek HV, Cushing SL, Papsin BC, Gordon KA. Cochlear implant use remains consistent over time in children with single-sided deafness. Ear Hear 2020;41(03):678-685

57. Deep NL, Gordon SA, Shapiro WH, Waltzman SB, Roland JT Jr, Friedmann DR. Cochlear implantation in children with single-sided deafness. Laryngoscope 2021;131(01):E271-E277

58. Arndt S, Laszig R, Aschendorff A, Hassepass F, Beck R, Wesarg T. Cochlear implant treatment of patients with single-sided deafness or asymmetric hearing loss. HNO 2017;65(Suppl 2):98-108

59. Speck I, Challier P, Wesarg T, et al. Is the cochlear implant a successful long-term solution for singlesided deaf and asymmetric hearing-impaired patients? Eur Arch Otorhinolaryngol 2021;278 (09):3257-3265

60. Polonenko MJ, Papsin BC, Gordon KA. Children with single-sided deafness use their cochlear implant. Ear Hear 2017;38(06):681-689

61. Lee H-J, Smieja D, Polonenko MJ, Cushing SL, Papsin BC, Gordon KA. Consistent and chronic cochlear implant use partially reverses cortical effects of single sided deafness in children. Sci Rep 2020;10(01):21526

62. Burton H, Firszt JB, Holden T, Agato A, Uchanski RM. Activation lateralization in human core, belt, and parabelt auditory fields with unilateral deafness compared to normal hearing. Brain Res 2012;1454:33-47

63. Steel MM, Papsin BC, Gordon KA. Binaural fusion and listening effort in children who use bilateral cochlear implants: a psychoacoustic and pupillometric study. PLoS One 2015;10(02):e0117611
64. Kral A, Kronenberger WG, Pisoni DB, O’Donoghue GM. Neurocognitive factors in sensory restoration of early deafness: a connectome model. Lancet Neurol 2016;15(06):610-621

65. Pisoni DB, Kronenberger WG, Chandramouli SH, Conway CM. Learning and memory processes following cochlear implantation: the missing piece of the puzzle. Front Psychol 2016;7:493

66. Beijen J, Snik AF, Straatman LV, Mylanus EA, Mens LH. Sound localization and binaural hearing in children with a hearing aid and a cochlear implant. Audiol Neurotol 2010;15(01):36-43

67. Grieco-Calub TM, Litovsky RY. Sound localization skills in children who use bilateral cochlear implants and in children with normal acoustic hearing. Ear Hear 2010;31(05):645-656

68. Killan C, Scally A, Killan E, Totten C, Raine C. Factors affecting sound-source localization in children with simultaneous or sequential bilateral cochlear implants. Ear Hear 2019;40(04):870-877

69. Ehlers E, Goupell MJ, Zheng Y, Godar SP, Litovsky RY. Binaural sensitivity in children who use bilateral cochlear implants. J Acoust Soc Am 2017;141(06):4264

70. Gordon KA, Deighton MR, Abbasalipour P, Papsin BC. Perception of binaural cues develops in children who are deaf through bilateral cochlear implantation. PLoS One 2014;9(12):e114841

71. Kan A, Litovsky RY, Goupell MJ. Effects of interaural pitch matching and auditory image centering on binaural sensitivity in cochlear implant users. Ear Hear 2015;36(03):e62-e68

72. Dietz M. Models of the electrically stimulated binaural system: a review. Network 2016;27(23):186-211

73. AronoffJM, Yoon YS, Freed DJ, Vermiglio AJ, Pal I, Soli SD. The use of interaural time and level difference cues by bilateral cochlear implant users. J Acoust Soc Am 2010;127(03):EL87-EL92

74. Bernstein JGW, Stakhovskaya OA, Schuchman GI, Jensen KK, Goupell MJ. Interaural time-difference discrimination as a measure of place of stimulation for cochlear-implant users with single-sided deafness. Trends Hear 2018;22:2331216518765514

75. Cushing SL, Papsin BC, Rutka JA, James AL, Gordon KA. Evidence of vestibular and balance dysfunction in children with profound sensorineural hearing loss using cochlear implants. Laryngoscope 2008;118(10):1814-1823

76. Sokolov M, Gordon KA, Polonenko M, Blaser SI, Papsin BC, Cushing SL. Vestibular and balance function is often impaired in children with profound unilateral sensorineural hearing loss. Hear Res 2019;372:52-61 